\title{
Kinetic reference potential, pH-effect, and energy recovery in electrolysis of water ${ }^{\dagger}$
}

\author{
Tobias Binninger, ${ }^{* a}$ Adrian Heinritz, ${ }^{b}$ and Rhiyaad Mohamed ${ }^{* c}$
}

The electrolysis of water will likely become of superior importance for a sustainable energy economy. However, the electrocatalysis of electrochemical water splitting is complicated and the origin of significant energy losses. Among the heavily discussed open questions in this field at present is the origin of experimentally observed differences between electrolysis kinetics in acidic vs. alkaline electrolyte, and the effect of high-pressure operation on electrolyser performance. Our thermodynamic analysis reveals answers and fundamental connections between these questions by the definition of balanced reactive conditions and the kinetic reference voltage of the electrolysis reaction. Unlike the reversible cell voltage, the kinetic reference voltage $U_{\text {kin }}$ is not biased by product $\mathrm{H}_{2}$ and $\mathrm{O}_{2}$ concentrations, and it represents a reliable intrinsic reference point for electrolysis kinetics. At standard temperature $T=25^{\circ} \mathrm{C}$, its value is $U_{\text {kin }}=1.441 \mathrm{~V}$, which is in remarkable agreement with commonly observed onset voltages for macroscopic electrolysis rates. We define the reactive excess overvoltage $\eta_{\mathrm{rxs}}=U_{\text {kin }}-U_{\text {rev }}$ as the difference between the kinetic reference voltage and the reversible cell voltage. Comparing the hydrogen evolution (HER) and oxygen evolution (OER) half-cell reactions in acidic vs. alkaline electrolyte, we find an asymmetric and $\mathrm{pH}$-dependent distribution of $\eta_{\mathrm{rxs}}$ among HER and OER. Increasing the electrolysis gas pressure results in a reduction of $\eta_{\text {rxs }}$ due to an increased free energy content of the evolved gases. Our analysis provides a new perspective on activation losses in water electrolysis, on pH-effects in hydrogen and oxygen evolution electrocatalysis, and on high-pressure electrolysis as a means for energy recovery.

\section{Broader Context}

With record-breaking global temperatures and carbon dioxide emissions, the transition of our civilisation from its present fossil fuel basis to a sustainable and carbon-neutral foundation becomes dramatically urgent. This will require massive generation of "clean" hydrogen by electrolytic water splitting (power-to-gas), both for energy storage and for industrial feedstock supply. The upscaling of water electrolysis to an industrial cornerstone technology is hindered by its limited energy efficiency, which is largely attributed to the sluggish reaction kinetics requiring expensive electrocatalysts. Therefore, large research resources are currently devoted to the quest for better and cheaper electrocatalyst materials. The water splitting kinetics were found to depend strongly on the type of electrolyte used, i.e. acidic vs. alkaline, and also being influenced by the process gas pressure. However, the origins of these effects remain under debate. In the present work, we develop a thermodynamic framework that offers a common intuitive explanation for both $\mathrm{pH}$ - and pressure effects in water splitting electrocatalysis. Our results correspond to a paradigm change, because we show that the intrinsic reference voltage, at

\footnotetext{
a ICGM, UM, CNRS, ENSCM, Montpellier, France.

E-mail: tobias.binninger.science@gmx.de

${ }^{b}$ Electrochemistry Laboratory, Paul Scherrer Institut, 5232 Villigen, Switzerland.

${ }^{c}$ HySA/Catalysis Centre of Competence, Catalysis Institute, Department of Chemical Engineering, University of Cape Town, 7701, South Africa.

E-mail: rhiyaad.mohamed@uct.ac.za

$\dagger$ Electronic Supplementary Information (ESI) available: Reactive excess Gibbs free energy in water electrolysis and its connection with the kinetic reference potential.
}

which technically relevant water splitting rates can be achieved, is shifted with respect to the commonly used reversible equilibrium voltage, with profound consequences for the field.

\section{Introduction}

Electrolysis is an envisaged cornerstone of a sustainable economy, ${ }^{1}$ because it is key for power-to-X (e.g. power-to-gas, powerto-liquid), 2,10 i.e. for the conversion of intermittent renewable primary energy sources to storable chemical energy carriers, especially hydrogen. Clean hydrogen is required for stationary and mobile electricity generation in fuel cells, but also as fundamental industrial feedstock, e.g. for methanol synthesis, for ammonia synthesis in the Haber-Bosch process, or for the Fischer-Tropsch synthesis of hydrocarbons. The transformation from traditional fossil fuel-based economy to a "hydrogen economy" is not only crucial for the reduction of carbon dioxide emissions and the fight against global warming, but it also offers huge potential for future economic development as acknowledged by current economic policy strategies. Thus, at present, the importance of clean hydrogen production from electrocatalytic (or photocatalytic) water splitting appears overwhelming.

Energy efficiency is essential for a process that could become a hub for the transformation of a significant fraction of the gross energy turnover at national or even global scales. Even small efficiency improvements can enable gigawatt-savings in primary energy. The energy efficiency of the electrolysis process is typically calculated based on the higher heating value (HHV) of the produced hydrogen, i.e. its heat of combustion (reaction en- 
thalpy) for product water in the liquid state, that amounts to $285.83 \mathrm{~kJ} \mathrm{~mol}^{-1}$ (or $2.962 \mathrm{eV}$ per $\mathrm{H}_{2}$ molecule) at standard conditions ( $\left.T=25^{\circ} \mathrm{C}, p=1 \mathrm{bar}\right) .11$ Since two electrons are required to form one $\mathrm{H}_{2}$ molecule, the HHV corresponds to the thermoneutral cell voltage $U_{\text {thn }}=\Delta H_{\mathrm{r}} /(2 e)=1.481 \mathrm{~V}$ (evaluated at standard conditions), where $\Delta H_{\mathrm{r}}>0$ is the reaction enthalpy of the endothermic water splitting process. At the thermoneutral voltage $U_{\text {thn }}$, the net heat production of the electrolysis reaction is zero. Typical electrolyser operation cell voltages of $U_{\text {cell }} \approx 1.8-2.0 \mathrm{~V}$ yield an energy efficiency of $\varepsilon_{\mathrm{HHV}}=U_{\text {thn }} / U_{\text {cell }} \approx 75-80 \%$.

The thermodynamic equilibrium voltage is given by the reversible cell voltage $U_{\mathrm{rev}}=\Delta G_{\mathrm{r}} /(2 e)=1.229 \mathrm{~V}$ (evaluated at standard conditions), 11 where $\Delta G_{\mathrm{r}}>0$ is the Gibbs free energy of the water splitting reaction $\mathrm{H}_{2} \mathrm{O} \rightleftharpoons \mathrm{H}_{2}+(1 / 2) \mathrm{O}_{2}$. At $U_{\text {rev }}$, the water splitting (left-to-right) and water formation (right-to-left) reactions are balanced and the net current is zero. Thus, theoretically, $U_{\text {rev }}$ is the minimum cell voltage required for water splitting. For this reason, the energetic losses in an electrolyser are often analysed w.r.t. $U_{\text {rev }}$ (rather than $U_{\text {thn }}$ ), expressed in the reversible voltage efficiency $\varepsilon_{\mathrm{rev}}=U_{\mathrm{rev}} / U_{\text {cell }} \approx 60-70 \%$ (again evaluated for $U_{\text {cell }} \approx 1.8-2.0 \mathrm{~V}$ ). Besides losses resulting from ionic and electronic ohmic resistance and from mass transport limitations, the kinetic losses represent a dominant contribution. They are mostly attributed to the sluggishness of the oxygen evolution reaction (OER) at the electrolyser anode, although the hydrogen evolution reaction (HER) at the cathode also matters, especially in alkaline conditions. Kinetic losses are quantified in terms of the kinetic overvoltage $\eta_{\text {kin }}=U_{\text {cell }}^{\text {corr }}-U_{\text {rev }}$ that is given by the difference between the ohmic- and mass-transport-loss corrected cell voltage and the reversible cell voltage. The kinetic overvoltage is the sum of the OER and HER half-cell kinetic overpotentials, $\eta_{\text {kin }}=\eta_{\text {kin }}^{\text {OER }}+\eta_{\text {kin }}^{\text {HER }}$, where $\eta_{\text {kin }}^{\text {OER/HER }}$ are measured w.r.t. the corresponding half-cell equilibrium potentials $E_{\mathrm{rev}}^{\mathrm{OER} / \mathrm{HER} \ddagger}$ The kinetic overvoltage typically contributes $\approx 0.4 \mathrm{~V}$ to the cell voltage, and thus represents an absolute $\approx 25 \%$ reduction in the reversible efficiency of the electrolyser. Consequently, the hope for significant efficiency improvements is associated with the search for better catalyst materials for OER $[2,38$ and HER, $, 39,48$ which therefore represents one of the greatest challenges in present electrocatalysis research. 49

In alkaline electrolyte, the HER has slower kinetics, and thus requires a larger overpotential $\eta_{\text {kin }}^{\mathrm{HER}}$ than in acidic electrolyte. To explain this pH-effect, it was proposed that the water dissociation step was the limiting factor in alkaline.40|45|49 This view has been contradicted, $\underline{41}$ and, instead, an influence of the $\mathrm{pH}$ value on the binding energies of HER reaction intermediates at the electrocatalyst surface has been suggested. $41 / 42$ Alternatively, entropic barriers for proton transfer at the catalyst surface have been put forward, $\frac{46,48}{4}$ and the role of interfacial water reorganisation has been highlighted. $\frac{50}{50}$ Thus, the origin of the $\mathrm{pH}$-effect in HER electrocatalysis is currently under debate.

High-pressure electrolysis at operating pressures $p \approx 100 \mathrm{bar}$ and above directly generates pressurized hydrogen, which re-

$\ddagger$ We denote cell voltages by $U$ and half-cell electrode potentials by $E$. duces (or eliminates) the subsequent compression requirement for storage. Interestingly, it has been observed that increasing the pressure level, especially at the OER anode, did not result in increased cell voltage and power consumption, 51,54 although the latter was expected from the increased reversible cell voltage according to the Nernst equation (log denotes the natural logarithm)

$$
U_{\mathrm{rev}}\left(p_{\mathrm{H}_{2}}, p_{\mathrm{O}_{2}}, T\right)=U_{\mathrm{rev}}^{\ominus}(T)+\frac{R T}{2 F} \log \left[\left(\frac{p_{\mathrm{H}_{2}}}{p^{\ominus}}\right)\left(\frac{p_{\mathrm{O}_{2}}}{p^{\ominus}}\right)^{1 / 2}\right]
$$

where $R$ is the gas constant, $F$ the Faraday constant, $U_{\text {rev }}^{\ominus}(T)$ the reversible cell voltage at standard pressure $p^{\ominus}=1$ bar and operation temperature $T$, and $p_{\mathrm{H}_{2} / \mathrm{O}_{2}}$ the respective operation partial pressures. Thus, high-pressure electrolysis appears to offer pressurization of output gases "for free". The hypothesis was proposed that the increased pressure could enhance the reaction kinetics and compensate for the shift of the reversible voltage, 53 but the exact origin of this pressure effect remains debated.

In the present work, we develop a common framework for the explanation of both $\mathrm{pH}$ - and pressure effects in water electrolysis. At the same time, our analysis reveals boundaries to the voltage efficiency gains expectable from electrocatalysis improvements, and identifies high-pressure electrolysis as a promising strategy for energy recovery.

\section{Theory}

The reversible cell voltage $U_{\text {rev }}$ corresponds to thermodynamic equilibrium for the given electrolysis conditions $\left(T, p_{\mathrm{H}_{2}}, p_{\mathrm{O}_{2}}\right)$. For kinetic analysis, however, the relevance of $U_{\text {rev }}$ must be questioned. The problem lies in the fact that, e.g. at standard conditions $\left(^{\ominus}\right.$ ), the gas species $\mathrm{H}_{2}$ and $\mathrm{O}_{2}$ are considered at $p_{\mathrm{H}_{2}}^{\ominus}=p_{\mathrm{O}_{2}}^{\ominus}=1$ bar, whereas water is in the liquid state. The associated concentrations of the $\mathrm{H}_{2} \mathrm{O}$ reactant, on the one hand, and of the $\mathrm{H}_{2}$ and $\mathrm{O}_{2}$ products, on the other hand, are extremely unbalanced: The electrocatalytic water splitting reaction produces $\mathrm{H}_{2}$ and $\mathrm{O}_{2}$ molecules in the dissolved state at microscopic proximity to the electrocatalyst surface. Only in a subsequent step, they escape to the gas phase, or form gas bubbles from the locally over-saturated electrolyte. Thus, at standard conditions and $T=25^{\circ} \mathrm{C}$, the actual product concentrations are $c_{\mathrm{H}_{2} \text {,sat }}^{\ominus}=$ $0.771 \times 10^{-3} \mathrm{~mol} \mathrm{~L}^{-1}\left(\mathrm{H}_{2} \text { saturation concentration in water }\right)^{55}$ and $c_{\mathrm{O}_{2} \text {,sat }}^{\ominus}=1.252 \times 10^{-3} \mathrm{~mol} \mathrm{~L}^{-1}\left(\mathrm{O}_{2}\right.$ saturation concentration in water). $\sqrt[56]{ }$ These are several orders of magnitude smaller than the liquid water reactant concentration $c_{\mathrm{H}_{2} \mathrm{O}, \ell}^{\ominus}=55.34 \mathrm{~mol} \mathrm{~L}^{-1} . \underline{57}$ This unbalance strongly biases the reversible cell voltage, but, in fact, the low $\mathrm{H}_{2}$ and $\mathrm{O}_{2}$ product concentrations do not influence the rate of the water splitting reaction direction. Therefore, $U_{\text {rev }}^{\ominus}$ is a questionable, and even arbitrary, reference for an analysis of the reaction kinetics of electrolytic water splitting.

\section{Balanced reactive conditions}

To define reference conditions with balanced reactant and product concentrations, a first choice could be 1-molar concentrations for all, $c_{\mathrm{H}_{2} \mathrm{O}}=c_{\mathrm{H}_{2}}=c_{\mathrm{O}_{2}}=1 \mathrm{~mol} \mathrm{~L}^{-1}$, which is the standard concentration typically defined for dissolved species. How- 

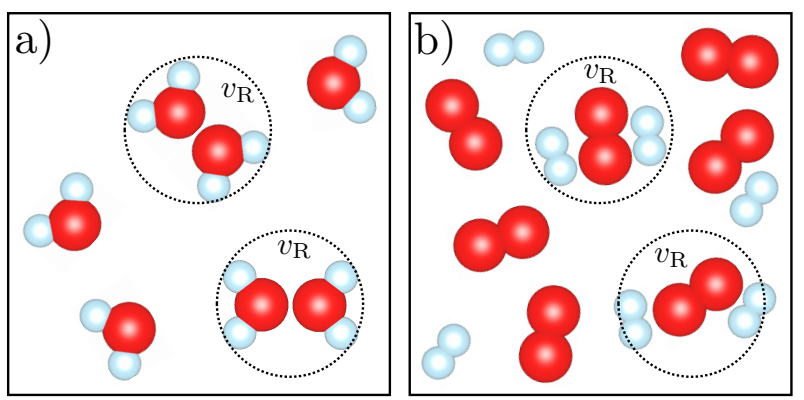

Fig. 1 Schematic visualisation of the concept of balanced reactive conditions: The number (i.e. concentration) of stoichiometric encounters (indicated by dotted circles) of $\mathrm{H}_{2} \mathrm{O}$ molecules for water splitting in (a) is equal to the number of stoichiometric encounters of $\mathrm{H}_{2}$ and $\mathrm{O}_{2}$ molecules for water formation in (b). Oxygen atoms are shown in red, hydrogen atoms in light blue, and $v_{\mathrm{R}}$ is the reactive volume.

ever, as becomes apparent later, this would result in reference potentials that depend on the number of water molecules explicitly written in the reaction equation. Also, liquid water with 1molar concentration appears intuitively unreasonable. Alternatively, one could define balanced reference conditions requiring equal concentration products for both sides of the reaction equation $2 \mathrm{H}_{2} \mathrm{O} \rightleftharpoons 2 \mathrm{H}_{2}+\mathrm{O}_{2}$, i.e. $c_{\mathrm{H}_{2}}^{2} c_{\mathrm{O}_{2}}=c_{\mathrm{H}_{2} \mathrm{O}}^{2}$. However, the latter relation is physically unreasonable, because of non-matching units between the left and right hand side. In the following, we show how this problem can be solved and consistent, intrinsic reference conditions defined.

We first transform the Nernst equation (11) into a form involving the concentrations of dissolved gas species. Applying Henry's law for the saturation concentrations, $p_{\mathrm{H}_{2}} / p^{\ominus}=c_{\mathrm{H}_{2}} / c_{\mathrm{H}_{2} \text {,sat }}^{\ominus}$ and $p_{\mathrm{O}_{2}} / p^{\ominus}=c_{\mathrm{O}_{2}} / c_{\mathrm{O}_{2}, \text { sat }}^{\ominus}$, the Nernst equation reads

$$
U_{\text {rev }}\left(c_{\mathrm{H}_{2}}, c_{\mathrm{O}_{2}}, T\right)=U_{\text {rev }}^{\ominus}(T)+\frac{R T}{2 F} \log \left[\left(\frac{c_{\mathrm{H}_{2}}}{c_{\mathrm{H}_{2}, \text { sat }}^{\ominus}}\right)\left(\frac{c_{\mathrm{O}_{2}}}{c_{\mathrm{O}_{2}, \text { sat }}^{\ominus}}\right)^{1 / 2}\right]
$$

The concentration-dependent term in this equation essentially originates from the entropy of ideal gases. Real gases and dissolved species do not strictly follow this behavior, and, strictly speaking, concentrations must be replaced by activities in Eq. (2). However, these deviations are generally small and the dominant part of the concentration-dependence is unspecific and ideal-gaslike. We seek to correct the concentration unbalance of the unspecific ideal-gas contribution to the reversible cell voltage, while preserving any species-specific influence.

For this purpose, we consider a hypothetical system where all reactants and products, i.e. $\mathrm{H}_{2} \mathrm{O}, \mathrm{H}_{2}$, and $\mathrm{O}_{2}$, follow ideal gas statistics, and we propose the principle of balanced reactive conditions: We require that the number (per volume, i.e. concentration) of stoichiometric molecular encounters for both sides of the reaction equation $2 \mathrm{H}_{2} \mathrm{O} \rightleftharpoons 2 \mathrm{H}_{2}+\mathrm{O}_{2}$ are equal (on average over time), as schematically visualised in Fig. 1. By stoichiometric encounter, we mean that a stoichiometric number of molecules, as defined by the reaction equation, meet within a short distance that would allow the molecules to interact and hypothetically re- act. We call this distance the "reactive distance" $r_{\mathrm{R}}$ and the corresponding spherical volume the "reactive volume" $\nu_{R}=(4 / 3) \pi r_{R}^{3}$. It is important to note that we do not imply any assumption, or model, about a specific reaction mechanism. We merely count the number of suitable molecular encounters in abstract ideal gas mixtures.

For the water splitting direction, a stoichiometric encounter is a pair of water molecules at a distance smaller than $r_{\mathrm{R}}$, cf. Fig. 17. If the total volume is $V$ and the total number of water molecules is $N_{\mathrm{H}_{2} \mathrm{O}}$, the probability of finding a second water molecule within the distance $r_{\mathrm{R}}$ (i.e. within the reactive volume $v_{R}$ ) around any given water molecule is equal t ${ }^{\S}$ $N_{\mathrm{H}_{2} \mathrm{O}}\left(v_{\mathrm{R}} / V\right)$, and the total number of stoichiometric encounters therefore is $N_{\mathrm{R}}^{\text {split }}=N_{\mathrm{H}_{2} \mathrm{O}}^{2}\left(v_{\mathrm{R}} / V\right) / 2$ ! with corresponding concentration $c_{\mathrm{R}}^{\text {split }}=N_{\mathrm{R}}^{\text {split }} / V=v_{\mathrm{R}} c_{\mathrm{H}_{2} \mathrm{O}}^{2} / 2$ !. Similarly, the concentration of stoichiometric encounters for the water formation direction, cf. Fig. 11p, is given by $c_{\mathrm{R}}^{\text {form }}=v_{\mathrm{R}}^{2} c_{\mathrm{H}_{2}}^{2} c_{\mathrm{O}_{2}} / 2$ !. For equal concentrations (i.e. rates) of stoichiometric encounters, $c_{\mathrm{R}}^{\text {split }}=c_{\mathrm{R}}^{\text {form }}$, we find $v_{\mathrm{R}} c_{\mathrm{H}_{2} \mathrm{O}}^{2} / 2 !=v_{\mathrm{R}}^{2} c_{\mathrm{H}_{2}}^{2} c_{\mathrm{O}_{2}} / 2$ !, and thus

$$
\frac{c_{\mathrm{H}_{2}}^{2} c_{\mathrm{O}_{2}}}{c_{\mathrm{H}_{2} \mathrm{O}}^{2}}=\frac{1}{v_{\mathrm{R}}}=c^{\mathrm{R}}
$$

We call $c^{\mathrm{R}}$ the reactive concentration, which is determined by the reactive distance $r_{\mathrm{R}}$. For water splitting/formation, the most natural choice of the latter is the length of a hydrogen bond, $r_{\mathrm{R}} \approx 2 \AA$, which yields $c^{\mathrm{R}}=1 / v_{\mathrm{R}} \approx c_{\mathrm{H}_{2} \mathrm{O}, \ell}$. We therefore define the reactive concentration of water splitting/formation to be equal to the concentration of liquid water at the given temperature

$$
c^{\mathrm{R}}(T)=c_{\mathrm{H}_{2}, \ell}(T)
$$

Upon inserting Eq. (4) into Eq. (3), we obtain the defining relation for balanced reactive conditions,

$$
c_{\mathrm{H}_{2}}^{2} c_{\mathrm{O}_{2}}=\left(c^{\mathrm{R}}\right)^{3}=c_{\mathrm{H}_{2} \mathrm{O}, \ell}^{3}
$$

It is highly interesting to note that this relation is similar to the previously discussed relation of equal concentration products, however with an additional water concentration factor on the right hand side of relation (5) that matches the units on both sides.

\section{Kinetic reference voltage}

At balanced reactive conditions, the concentrations of gas species fulfill relation (5). Inserting this into Eq. (2), we define the kinetic

$\S$ According to our definition, we consider ideal gas statistics, i.e. uniform density distribution and pair correlation function.

T We divide by 2 ! to avoid double-counting of pairs of molecules. 
reference voltage

$$
\begin{aligned}
U_{\text {kin }}(T) & =U_{\text {rev }}^{\ominus}(T)+\frac{R T}{2 F} \log \left[\left(\frac{c^{\mathrm{R}}}{c_{\mathrm{H}_{2}, \text { sat }}^{\ominus}}\right)\left(\frac{c^{\mathrm{R}}}{c_{\mathrm{O}_{2}, \text { sat }}}\right)^{1 / 2}\right] \\
& =U_{\text {rev }}^{\ominus}(T)+\frac{R T}{2 F} \log \left[\left(\frac{p_{\mathrm{H}_{2}}^{\mathrm{R}}}{p^{\ominus}}\right)\left(\frac{p_{\mathrm{O}_{2}}^{\mathrm{R}}}{p^{\ominus}}\right)^{1 / 2}\right]
\end{aligned}
$$

In the second step, we again applied Henry's law to define the reactive hydrogen and oxygen pressures $p_{\mathrm{H}_{2}}^{\mathrm{R}}=\left(c^{\mathrm{R}} / c_{\mathrm{H}_{2}, \text { sat }}^{\ominus}\right) p^{\ominus}$ and $p_{\mathrm{O}_{2}}^{\mathrm{R}}=\left(c^{\mathrm{R}} / c_{\mathrm{O}_{2}, \text { sat }}^{\ominus}\right) p^{\ominus}$, respectively. At $T=25^{\circ} \mathrm{C}$, we have $p_{\mathrm{H}_{2}}^{\mathrm{R}}=$ $71.8 \times 10^{3}$ bar and $p_{\mathrm{O}_{2}}^{\mathrm{R}}=44.2 \times 10^{3}$ bar, and the kinetic reference voltage is $U_{\text {kin }}=1.441 \mathrm{~V}$. The value of $U_{\text {kin }}(T)$ is very stable as a function of temperature, e.g. $U_{\mathrm{kin}}\left(T=80^{\circ} \mathrm{C}\right)=1.438 \mathrm{~V}$.

It should be noted that the value of the kinetic reference voltage depends only weakly on the exact choice of $c^{\mathrm{R}}$. Even a change by a factor of 8 (change of $r_{\mathrm{R}}$ by factor $1 / 2$ ) shifts $U_{\text {kin }}\left(T=25^{\circ} \mathrm{C}\right.$ ) by $\approx 0.01 \mathrm{~V}$ only. The specific choice (4) is most advantageous, because it makes the kinetic reference potentials of the half-cell reactions independent of the number of water molecules explicitly written in the reaction equations, see below.

Also, $U_{\text {kin }}$ is largely independent of the actual reference pressures $p^{\ominus}$ chosen, because any change of these produces a shift of $U_{\text {rev }}^{\ominus}$ that is compensating the change in the second term in Eq. (7). Therefore, we can write $U_{\text {kin }} \approx U_{\text {rev }}\left(p_{\mathrm{H}_{2}}^{\mathrm{R}}, p_{\mathrm{O}_{2}}^{\mathrm{R}}\right)$, where " $\approx$ " acknowledges that the exact $U_{\text {rev }}$ as a function of pressures generally deviates slightly from the ideal gas behaviour described by the second term in Eq. (7), especially for such large reactive pressures $p_{\mathrm{H}_{2}}^{\mathrm{R}}$ and $p_{\mathrm{O}_{2}}^{\mathrm{R}}$. This subtle difference, however, enables a distinct physical interpretation of $U_{\text {kin }}$. The ideal gas term in Eq. (7) serves as a correction of the large entropy difference contained in $U_{\text {rev }}^{\ominus}$ that simply arises from the large difference in the respective product and reactant concentrations. This concentration-entropy difference is biasing the standard reversible equilibrium voltage $U_{\text {rev }}^{\ominus}$, and it is naturally corrected by the corresponding concentration-entropy terms of ideal gases. As a consequence, $U_{\text {kin }}$ acquires the physical meaning of the reference voltage determined by the reactive excess (rxs) Gibbs free en$\operatorname{ergy} \Delta G_{\mathrm{r}}^{\mathrm{rxs}}$ of the water splitting reaction, where "excess" means that we refer all thermodynamic quantities to their reference values for atomic ideal gases in analogy to the notion of the excess entropy atomic ideal gases at equivalent (balanced) reactive concentrations for each species. This interpretation is further elaborated in the ESI ${ }^{\dagger}$.

Definition (6) can be generalised to define the kinetic reference voltage $U_{\text {kin }}$ for any electrochemical reaction (and the kinetic reference potential $E_{\text {kin }}$ for any half-cell reaction). Interestingly, for simple electrochemical redox couples of the form Red $\rightleftharpoons \mathrm{Ox}+\mathrm{e}^{-}$, where one reactant complex in solution is transformed via elec-

|| Note that here again, we use the principle of balanced reactive conditions to define the equivalent atomic ideal gas concentrations used for the correction. This slightly differs from the usual definition of "excess" where ideal gas correction is performed using the actual (atomic) concentrations.

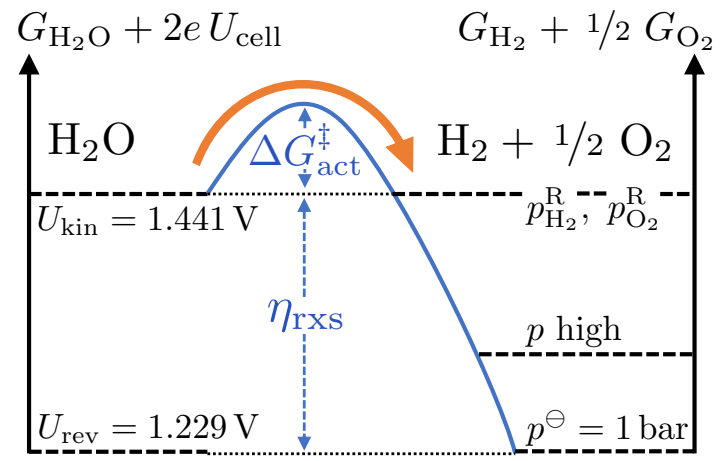

Fig. 2 Schematic free energy diagram for the electrochemical water splitting reaction. The electric energy contribution $2 e U_{\text {cell }}$ adds to the reactant side. The gas pressures of product hydrogen and oxygen affect the free energy of the product side.

tron transfer into one product complex in solution, the kinetic reference potential $E_{\mathrm{kin}}$ is strictly equal to the standard equilibrium potential $E_{\mathrm{rev}}^{\ominus}$. Here, standard conditions are already balanced, $c_{\mathrm{Red}}^{\ominus}=c_{\mathrm{Ox}}^{\ominus}=1 \mathrm{~mol} \mathrm{~L}^{-1}$, and thus $\log \left[\left(c^{\mathrm{R}} / c_{\mathrm{Ox}}^{\ominus}\right)\left(c^{\mathrm{R}} / c_{\mathrm{Red}}^{\ominus}\right)^{-1}\right]=0$ regardless of the choice of $c^{\mathrm{R}}$. In the case of water splitting, we consider the kinetic reference voltage, rather than the reversible voltage, as the analogue to standard equilibrium potentials of simple redox couples. We then explain the absence of macroscopic water splitting rates at $U_{\text {rev }}$ by the significant negative shift of $U_{\text {rev }}$ w.r.t. $U_{\text {kin }}$ that results from the strong imbalance between the liquid water reactant concentration and the $\mathrm{H}_{2}$ and $\mathrm{O}_{2}$ product concentrations at standard conditions. This situation is analogous to the situation of a simple electrochemical redox couple with strongly imbalanced concentrations, e.g. $c_{\mathrm{Ox}}=0.001 \mathrm{~mol} \mathrm{~L}^{-1}$ and $c_{\text {Red }}=1 \mathrm{~mol} \mathrm{~L}^{-1}$. According to the Nernst equation, the corresponding equilibrium potential $E_{\mathrm{rev}}\left(c_{\mathrm{Ox}}, c_{\mathrm{Red}}\right)<E_{\mathrm{rev}}^{\ominus}$ is significantly negatively shifted w.r.t. the standard equilibrium potential, and it is therefore not surprising if no macroscopic reaction rate Red $\rightarrow \mathrm{Ox}+\mathrm{e}^{-}$can be observed at $E_{\text {rev }}\left(c_{\mathrm{Ox}}, c_{\mathrm{Red}}\right)$.

Liquid water electrolysis. Fig. 2 schematically shows the free energy diagram of the electrochemical water splitting reaction for water in the liquid state at $T=25^{\circ} \mathrm{C}$. At the kinetic reference voltage $U_{\text {kin }}=1.441 \mathrm{~V}$, the water splitting reaction is at equilibrium for hydrogen and oxygen gases at balanced reactive conditions with liquid water. These are characterised by the reactive pressures $p_{\mathrm{H}_{2}}^{\mathrm{R}}$ and $p_{\mathrm{O}_{2}}^{\mathrm{R}}$, respectively. At $U_{\text {kin }}$, the water splitting reaction is still activated, but for efficient catalyst materials, the activation barrier $\Delta G_{\text {act }}^{\ddagger}$ is sufficiently small to enable macroscopic reaction rates at cell voltages $U_{\text {cell }} \gtrsim U_{\text {kin }}$. Standard hydrogen and oxygen gas pressures of $p^{\ominus}=1 \mathrm{bar}$ are much smaller than the reactive pressures, and the corresponding Gibbs free energy of the product side is significantly decreased because of the pressure-dependent entropy contribution. This, however, does not affect the reactant side and the transition state at the top of the activation barrier. To attain equilibrium at standard conditions, the Gibbs free energy of the reactant side, which includes the electric energy contribution $2 e U_{\text {cell }}$, must be decreased accordingly by decreasing the cell voltage to the reversible voltage $U_{\text {rev }}=1.229 \mathrm{~V}$. We refer to the difference $\eta_{\mathrm{rxs}}=U_{\mathrm{kin}}-U_{\mathrm{rev}}$ as the reactive excess overvoltage, 


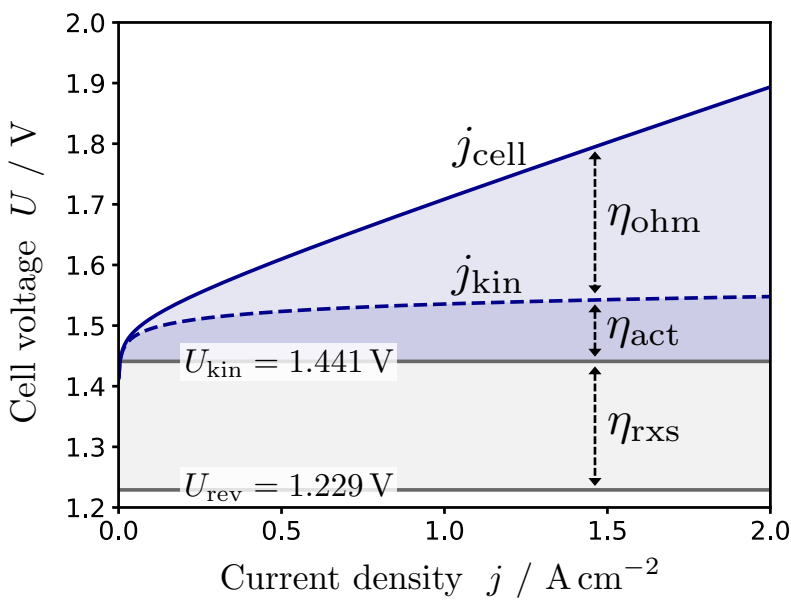

Fig. 3 Typical polarisation curve of a proton-exchange membrane (PEM) water splitting electrolyser utilising water in the liquid state. In the presented current density range, the mass-transport overvoltage $\eta_{\mathrm{mt}}$ is negligible and therefore not shown. The kinetic current density curve $j_{\text {kin }}$ is obtained after subtracting the ohmic overvoltage $\eta_{\text {ohm }}=R i_{\text {cell }}$ from the cell voltage $U$. The difference between the voltage defined by the $j_{\mathrm{kin}}$ curve and the kinetic reference voltage $U_{\text {kin }}$ is the activation overvoltage $\eta_{\text {act }}$. The reactive excess overvoltage $\eta_{\text {rxs }}$ results from the strong imbalance between the liquid water reactant concentration and the $\mathrm{H}_{2}$ and $\mathrm{O}_{2}$ product concentrations at standard conditions.

because it is equal to the excess free energy difference between standard conditions and balanced reactive conditions, see above and $\mathrm{ESI}^{\dagger}$. At $U_{\text {rev }}$, the water splitting reaction must overcome the sum of $\eta_{\mathrm{rxs}}+\Delta G_{\mathrm{act}}^{\ddagger}$, which is prohibitively large. As a consequence, water splitting is not detectable at or near $U_{\text {rev }}$, and the voltage region $U_{\text {rev }}<U_{\text {cell }}<U_{\text {kin }}$ remains largely inaccessible in the electrolysis of water.

Therefore, we suggest to (re-)define the activation overvoltage by $\eta_{\text {act }}=U_{\text {cell }}^{\text {corr }}-U_{\text {kin }}$, where $U_{\text {cell }}^{\text {corr }}=U_{\text {cell }}-\eta_{\text {ohm }}-\eta_{\text {mt }}$ is the corrected cell voltage after subtraction of the ohmic overvoltage $\eta_{\mathrm{ohm}}=R i_{\text {cell }}$ and possible mass-transport overvoltages $\eta_{\mathrm{mt}}$. Together with the reactive excess overvoltage $\eta_{\mathrm{rxs}}$ defined above, the total overvoltage $\eta=U_{\text {cell }}-U_{\text {rev }}=\eta_{\text {rxs }}+\eta_{\text {act }}+\eta_{\text {ohm }}+\eta_{\text {mt }}$ then splits into four contributions. Generally, up to medium scale current densities, the mass-transport overvoltage $\eta_{\mathrm{mt}}$ is not relevant. The other three overvoltage contributions are shown for a typical polarisation curve of a proton-exchange membrane (PEM) electrolyser in Fig. 3 The ohmic overvoltage $\eta_{\text {ohm }}$ can be reduced by decreasing the ionic and electronic resistances, and the activation overvoltage $\eta_{\text {act }}$ through improved electrocatalyst materials. The reactive excess overvoltage $\eta_{\mathrm{rxs}}$ can be reduced by increasing the electrolysis pressure level, which shifts the reversible voltage upwards towards the kinetic reference voltage that remains unaffected. This strategy enables energy recovery by high-pressure electrolysis operation, as discussed later.

It is interesting to note that the value of $U_{\text {kin }}$ lies close to the thermoneutral voltage $U_{\text {thn }}$. The kinetic reference voltage therefore naturally predicts that macroscopic water splitting rates only set in sufficiently close to isenthalpic conditions, which is in perfect agreement with the observed onset of water splitting around $U_{\text {cell }} \approx 1.4-1.5 \mathrm{~V}$, e.g. in polymer electrolyte electrolysers. 58
Steam electrolysis. How does the kinetic reference voltage change when going from liquid water electrolysis to hightemperature steam electrolysis? The reversible voltage is continuous as a function of temperature at the liquid-steam phase transition because of the equality of the Gibbs free energies of liquid and gaseous water at equilibrium. E.g., $U_{\mathrm{rev}}^{\ominus}\left(T=100^{\circ} \mathrm{C}\right)=1.167 \mathrm{~V}$ both for liquid water and for steam at $p^{\ominus}=1$ bar. In contrast, the kinetic reference voltage is discontinuous at the liquid-steam phase transition, because of the discontinuous change in density, and thus concentration. Inserting the corresponding liquid water molar concentration ${ }^{57}$ and molecular hydrogen ${ }^{55}$ and oxygen ${ }^{56}$ solubilities at $T=100^{\circ} \mathrm{C}$ into Eq. (6), we obtain $U_{\text {kin }}^{\text {liquid }}(T=$ $\left.100^{\circ} \mathrm{C}\right)=1.435 \mathrm{~V}$. In the case of steam electrolysis, the steam concentration term must be taken into account, because it is different from the reactive concentration Eq. (4), resulting in

$U_{\text {kin }}^{\text {steam }}(T)=U_{\text {rev }}^{\ominus}(T)+\frac{R T}{2 F} \log \left[\left(\frac{c^{\mathrm{R}}}{c_{\mathrm{H}_{2}, g}^{\ominus}}\right)\left(\frac{c^{\mathrm{R}}}{c_{\mathrm{O}_{2}, g}^{\ominus}}\right)^{1 / 2}\left(\frac{c^{\mathrm{R}}}{c_{\mathrm{H}_{2} \mathrm{O}, g}^{\ominus}}\right)^{-1}\right]$

where $c_{\mathrm{H}_{2}, g}^{\ominus}, c_{\mathrm{O}_{2}, g}^{\ominus}$, and $c_{\mathrm{H}_{2} \mathrm{O}, g}^{\ominus}$ are the concentrations of $\mathrm{H}_{2}, \mathrm{O}_{2}$, and $\mathrm{H}_{2} \mathrm{O}$ in the gas phase at given temperature $T$ and standard pressures $p_{\mathrm{H}_{2}}^{\ominus}=p_{\mathrm{O}_{2}}^{\ominus}=p_{\mathrm{H}_{2} \mathrm{O}, g}^{\ominus}=1$ bar. Assuming ideal gas behaviour, the gaseous concentrations are equal to $c_{\mathrm{H}_{2}, g}^{\ominus}=c_{\mathrm{O}_{2}, g}^{\ominus}=$ $c_{\mathrm{H}_{2} \mathrm{O}, g}^{\ominus}=c_{\text {ideal }, g}^{\ominus}=p^{\ominus} / R T$, which evaluates to $c_{\text {ideal }, g}^{\ominus}\left(T=100^{\circ} \mathrm{C}\right)=$ $32.23 \times 10^{-3} \mathrm{~mol} \mathrm{~L}^{-1}$. Together with $c^{\mathrm{R}}\left(T=100^{\circ} \mathrm{C}\right)=c_{\mathrm{H}_{2} \mathrm{O}, \ell}(T=$ $\left.100^{\circ} \mathrm{C}\right)=53.21 \mathrm{~mol} \mathrm{~L}^{-1}$,57 cf. Eq. (4), we obtain $U_{\text {kin }}^{\text {steam }}(T=$ $\left.100^{\circ} \mathrm{C}\right)=1.226 \mathrm{~V}$. It makes perfect physical sense that $U_{\text {kin }}^{\text {steam }}$ is reduced by $0.209 \mathrm{~V}$ compared to $U_{\text {kin }}^{\text {liquid }}$. In steam electrolysis, the cohesive energy of liquid water does not have to be overcome by the splitting reaction, which can be quantified by the latent heat of vaporisation of $0.423 \mathrm{eV}$ per $\mathrm{H}_{2} \mathrm{O}$ at $T=100^{\circ} \mathrm{C} .{ }^{59}$ Dividing this by $2 e$ (per split water molecule) almost precisely results in the difference $U_{\text {kin }}^{\text {liquid }}-U_{\text {kin }}^{\text {steam }}$. Steam electrolysis involves a much smaller reactive excess overvoltage $\eta_{\mathrm{rxs}}$ compared to liquid water electrolysis, and it enables operation close to the reversible voltage. However, the vaporisation heat must be provided at the preheating stage before the electrolyser. This effect could contribute to the recently observed overpotential reduction by in operando magnetic heating of electrocatalyst nanoparticles, 60 where the magnetic heating power must be taken into account in the total energy balance.

\section{pH-effect in HER and OER electrocatalysis}

The analysis of kinetic reference potentials also offers an explanation for the $\mathrm{pH}$-effects of the hydrogen and oxygen evolution reactions, HER and OER, respectively, and it further provides important insight into the corresponding reaction mechanisms. For a half-cell reaction like HER or OER, we refer to electrode potential $E$ rather than cell voltage $U_{\text {cell }}$.

Hydrogen evolution reaction. The HER in acid proceeds according to

$$
2 \mathrm{H}_{3} \mathrm{O}^{+}+2 \mathrm{e}^{-} \rightleftharpoons \mathrm{H}_{2}+2 \mathrm{H}_{2} \mathrm{O}
$$


and in alkaline according to

$$
2 \mathrm{H}_{2} \mathrm{O}+2 \mathrm{e}^{-} \rightleftharpoons \mathrm{H}_{2}+2 \mathrm{OH}^{-}
$$

The different nature of reactions (9) and (10) has been used as an explanation for the faster apparent kinetics of the HER in acid vs. alkaline.40145|49 However, both reactions are coupled via the water autoprotolysis reaction

$$
2 \mathrm{H}_{2} \mathrm{O} \rightleftharpoons \mathrm{H}_{3} \mathrm{O}^{+}+\mathrm{OH}^{-}
$$

and it has been argued that the fast rate of water autoprotolysis essentially equalises reactions (9) and (10).4146 Instead, to explain the $\mathrm{pH}$-effect, it was proposed that the $\mathrm{pH}$-value could influence the binding energies of HER reaction intermediates at the electrocatalyst surface. ${ }^{41 / 42}$ Other authors suggested an entropic barrier for the proton transfer at the electrocatalyst surface, $\underline{46}$ 48 or a larger reorganisation energy of the interfacial water layer 50 to explain the slower kinetics in alkaline conditions. Whereas such effects clearly influence HER rates in acid vs. alkaline, another perspective on the pH-effect is revealed by an analysis of the kinetic reference potentials. Using the reactive concentration Eq. (4), the kinetic reference potentials of the HER in acid and in alkaline are given by

$$
\begin{aligned}
E_{\text {kin }}^{\mathrm{HER}, a c i d} & =E_{\mathrm{RHE}}^{\mathrm{pH}=0}+\frac{R T}{2 F} \log \left[\left(\frac{c^{\mathrm{R}}}{c_{\mathrm{H}_{3} \mathrm{O}^{+}}^{\ominus}}\right)^{2}\left(\frac{c^{\mathrm{R}}}{c_{\mathrm{H}_{2}, \mathrm{sat}}^{\ominus}}\right)^{-1}\right] \\
E_{\text {kin }}^{\mathrm{HER}, \text { alk }} & =E_{\mathrm{RHE}}^{\mathrm{pH}=14}+\frac{R T}{2 F} \log \left[\left(\frac{c^{\mathrm{R}}}{c_{\mathrm{OH}^{-}}^{\ominus}}\right)^{-2}\left(\frac{c^{\mathrm{R}}}{c_{\mathrm{H}_{2}, \text { sat }}^{\ominus}}\right)^{-1}\right]
\end{aligned}
$$

respectively, where the corresponding standard concentrations are $c_{\mathrm{H}_{3} \mathrm{O}^{+}}^{\ominus}=c_{\mathrm{OH}^{-}}^{\ominus}=1 \mathrm{molL}^{-1}$, and where $E_{\mathrm{RHE}}^{\mathrm{pH}=0}$ and $E_{\mathrm{RHE}}^{\mathrm{pH}=14}$ are the reversible equilibrium potentials (reversible hydrogen electrode, RHE) at $\mathrm{pH}=0$ and $\mathrm{pH}=14$, respectively. Because of the specific choice of the reactive concentration Eq. (4), no water concentration correction terms appear in (12) and (13), which demonstrates the advantage of this choice. At $T=25^{\circ} \mathrm{C}$, the kinetic reference potentials are $E_{\text {kin }}^{\mathrm{HER} \text {,acid }}=E_{\mathrm{RHE}}^{\mathrm{pH}=0}-0.041 \mathrm{~V}$ and $E_{\mathrm{kin}}^{\mathrm{HER}, \text { alk }}=E_{\mathrm{RHE}}^{\mathrm{pH}=14}-0.247 \mathrm{~V}$, where $E_{\mathrm{RHE}}^{\mathrm{pH}=0}=0 \mathrm{~V}_{\mathrm{vs} \text {. SHE }}$ and $E_{\mathrm{RHE}}^{\mathrm{pH}=14}=-0.828 \mathrm{~V}_{\mathrm{vs} \text {. SHE}}$. Thus, to obtain intrinsic energetic alignment between HER reactant and product states, the electrode potential must be shifted negative w.r.t. the respective RHE potentials. In acidic conditions, this shift of $-0.041 \mathrm{~V}$ is rather small. Since concerted proton-electron transfer is extremely fast, it is not surprising that significant HER rates are already observable, e.g. on a Pt electrode, at the RHE potential slightly above the kinetic reference potential in acidic electrolyte. However, in alkaline conditions, the kinetic reference potential lies $-0.247 \mathrm{~V}$ negative from the RHE potential. Thus, comparing HER exchange current densities at RHE potentials implies different reactive excess overpotentials ${ }^{* *} \eta_{\mathrm{rxs}}^{\mathrm{HER}}=E_{\mathrm{kin}}^{\mathrm{HER}}-E_{\mathrm{RHE}}$ in acid vs. alkaline, and $\eta_{\mathrm{rxs}}^{\mathrm{HER}, \text { alk }}$ in alkaline is $-0.206 \mathrm{~V}$ more negative than $\eta_{\mathrm{rxs}}^{\mathrm{HER} \text {,acid }}$

$* *$ Because the HER is a reduction reaction, $\eta_{\mathrm{rxs}}$ is negative. in acidic conditions. We believe that this difference is one fundamental origin of the pH-effect in the electrocatalysis of HER and HOR (hydrogen oxidation reaction).

There are several points that support this view: Firstly, the present analysis is universal for any electrocatalyst, which agrees with experimental findings that the $\mathrm{pH}$-effect was very similar for $\mathrm{Pt} / \mathrm{C}, \mathrm{Ir} / \mathrm{C}$, and Pd/C. ${ }^{41}$ Secondly, using the experimentally determined alkaline HER Tafel slope of approx. $120 \mathrm{mV}$ per decade, 41 the additional $-0.206 \mathrm{~V}$ of the reactive excess overpotential in alkaline conditions (compared to acid) translates into a change of the kinetic HER current by a factor of approx. 50, which could represent a significant fraction of the experimentally observed factors of approx. 100-200 between the HER exchange current densities going from alkaline to acidic conditions. $\underline{41}$

Thirdly and most importantly, the $-0.206 \mathrm{~V}$ difference can be directly traced back to its physical origin. The equilibrium constant of the water autoprotolysis reaction (11) is commonly given as $K^{\mathrm{eq}}=1.0 \times 10^{-14}\left(\mathrm{~mol} \mathrm{~L}^{-1}\right)^{2}$. However, the water concentration factor is not included in this constant, and the truly intrinsic equilibrium constant is given by $K_{0}^{\mathrm{eq}}=$ $\left(c_{\mathrm{H}_{3} \mathrm{O}^{+}}^{\mathrm{eq}}\right)\left(c_{\mathrm{OH}^{-}}^{\mathrm{eq}}\right) /\left(c_{\mathrm{H}_{2} \mathrm{O}}\right)^{2}=K^{\mathrm{eq}} /\left(c_{\mathrm{H}_{2} \mathrm{O}}\right)^{2}=3.265 \times 10^{-18}$. This corresponds to a water dissociation energy of $-R T \log \left(K_{0}^{\mathrm{eq}}\right)=$ $99.81 \mathrm{~kJ} \mathrm{~mol}^{-1}=1.034 \mathrm{eV}$, which is exactly equal to the absolute difference between the HER kinetic reference potentials in acid and in alkaline, $E_{\mathrm{kin}}^{\mathrm{HER}, \text { alk }}-E_{\mathrm{kin}}^{\mathrm{HER} \text {,acid }}=-1.034 \mathrm{~V}$. The RHE potential shift of $E_{\mathrm{RHE}}^{\mathrm{pH}=14}-E_{\mathrm{RHE}}^{\mathrm{pH}=0}=-0.828 \mathrm{~V}$ going from acidic $(\mathrm{pH}=0)$ to alkaline $(\mathrm{pH}=14)$ conditions is not sufficient to provide the necessary extra energy of $1.034 \mathrm{eV}$ for water molecule dissociation, reaction (11), and therefore an additional $-0.206 \mathrm{~V}$ potential shift is required to obtain balanced energetic conditions for water dissociation in alkaline environment. Thus, the present analysis clearly identifies protolytic water dissociation as the rate limiting step at the RHE potential in alkaline electrolyte, as previously proposed by other authors. $40 / 45 / 49$

This conclusion has been challenged with the argument that the water dissociation reaction (11) is extremely fast, 4146 and therefore could not be rate limiting. Whereas this is true for the hydronium-hydroxide recombination, i.e. direction right to left, it is not true for the water protolysis, i.e. direction left to right. A simple estimation demonstrates this point, assuming that all protons donated from water molecules within a distance of $1 \mathrm{~nm}$ from the electrocatalyst surface are available for HER. The rate constant of the hydronium-hydroxide recombination reaction was reported with a value $k_{\text {rec }}=1.3 \times 10^{11} \mathrm{~s}^{-1}\left(\mathrm{~mol} \mathrm{~L}^{-1}\right)^{-1}, 61$ yielding a total recombination rate of $R_{\mathrm{rec}}=c_{\mathrm{H}_{3} \mathrm{O}^{+}}^{\mathrm{eq}} c_{\mathrm{OH}^{-}}^{\text {eq }} k_{\mathrm{rec}}=$ $1.3 \times 10^{-3} \mathrm{~mol} \mathrm{~L}^{-1} \mathrm{~s}^{-1}$, which, at equilibrium, is equal to the total water dissociation rate. Within the $1 \mathrm{~nm}$-thick surface layer, it corresponds to $1.3 \times 10^{-13} \mathrm{~mol} \mathrm{~cm}^{-2} \mathrm{~s}^{-1}$ water dissociation events, each of which contributing one proton. Therefore, the limiting (un-biased) HER current density would equal $1.3 \times 10^{-13} \mathrm{~F} \mathrm{~cm}^{-2} \mathrm{~s}^{-1}=12.5 \times 10^{-9} \mathrm{Acm}^{-2}$, which is negligibly small. Thus, the water protolysis step is most likely rate limiting for HER in alkaline conditions, and feasible HER rates require strong promotion of water protolysis by the presence of a catalyst surface and strong electrostatic fields within the electrochemical 
double-layer.

Oxygen evolution reaction. The OER in acid proceeds according to

$$
3 \mathrm{H}_{2} \mathrm{O} \rightleftharpoons \frac{1}{2} \mathrm{O}_{2}+2 \mathrm{H}_{3} \mathrm{O}^{+}+2 \mathrm{e}^{-}
$$

and in alkaline according to

$$
2 \mathrm{OH}^{-} \rightleftharpoons \frac{1}{2} \mathrm{O}_{2}+\mathrm{H}_{2} \mathrm{O}+2 \mathrm{e}^{-}
$$

The corresponding kinetic reference potentials are given by

$$
\begin{gathered}
E_{\text {kin }}^{\mathrm{OER}, \text { acid }}=E_{0, \mathrm{OER}}^{\mathrm{pH}=0}+\frac{R T}{2 F} \log \left[\left(\frac{c^{\mathrm{R}}}{c_{\mathrm{H}_{3} \mathrm{O}^{+}}^{\ominus}}\right)^{2}\left(\frac{c^{\mathrm{R}}}{c_{\mathrm{O}_{2}, \mathrm{sat}}^{\ominus}}\right)^{1 / 2}\right] \\
E_{\text {kin }}^{\mathrm{OER}, \text { alk }}=E_{0, \mathrm{OER}}^{\mathrm{pH}=14}+\frac{R T}{2 F} \log \left[\left(\frac{c^{\mathrm{R}}}{c_{\mathrm{OH}^{-}}^{\ominus}}\right)^{-2}\left(\frac{c^{\mathrm{R}}}{c_{\mathrm{O}_{2}, \text { sat }}^{\ominus}}\right)^{1 / 2}\right]
\end{gathered}
$$

respectively, where the corresponding standard concentrations are $c_{\mathrm{H}_{3} \mathrm{O}^{+}}^{\ominus}=c_{\mathrm{OH}^{-}}^{\ominus}=1 \mathrm{~mol} \mathrm{~L}^{-1}$, and where $E_{0, \mathrm{OER}}^{\mathrm{pH}=0}$ and $E_{0, \mathrm{OER}}^{\mathrm{pH}=14}$ are the reversible equilibrium potentials of the OER at $\mathrm{pH}=0$ and $\mathrm{pH}=14$, respectively. Again, because of the specific choice of the reactive concentration Eq. (4), no water concentration correction terms appear in (16) and (17). At $T=25^{\circ} \mathrm{C}$, the kinetic reference potentials are $E_{\text {kin }}^{\mathrm{OER}, \mathrm{acid}}=E_{0, \mathrm{OER}}^{\mathrm{pH}=0}+0.172 \mathrm{~V}$ and $E_{\text {kin }}^{\mathrm{OER}, \text { alk }}=E_{0, \mathrm{OER}}^{\mathrm{pH}=14}-0.034 \mathrm{~V}$, where $E_{0, \mathrm{OER}}^{\mathrm{pH}=0}=1.229 \mathrm{~V}_{\mathrm{vs} . \mathrm{SHE}}$ and $E_{0, \mathrm{OER}}^{\mathrm{pH}=14}=0.401 \mathrm{~V}_{\mathrm{vs} \text {. SHE}}$. Thus, to obtain energetic alignment between OER reactant and product states at balanced reactive conditions in acid, the electrode potential must be shifted positive w.r.t. the reversible equilibrium potential, and the resulting kinetic reference potential is $E_{\text {kin }}^{\mathrm{OER} \text {,acid }}=1.401 \mathrm{~V}$ vs. $\mathrm{RHE}(\mathrm{pH}=0)$. It is highly interesting to note that this value agrees very well with experimentally observed OER onset potentials in acid around 1.4$1.5 \mathrm{~V}$ vs. $\mathrm{RHE}(\mathrm{pH}=0)$ for the best catalysts, e.g. $\mathrm{RuO}_{2}$ and $\mathrm{IrO}_{2}$. 15/296263 Furthermore, based on linear relations between the binding energies of OER reaction intermediates at the electrocatalyst surface, a volcano plot of OER activities was constructed, 1264 and the top of the volcano, i.e. the optimal catalyst under the restriction of the linear scaling relations, was predicted at a potential around $1.5 \mathrm{~V}$ vs. $\mathrm{RHE}(\mathrm{pH}=0)$. Based on the present analysis, catalyst design strategies to achieve further significant reduction of the OER overpotential in acidic conditions appear optimistic. In alkaline conditions, however, an entirely different situation is found: The kinetic reference potential is shifted slightly negative w.r.t. the reversible equilibrium potential and equals $E_{\text {kin }}^{\text {OER,alk }}=1.195 \mathrm{~V}$ vs. $\mathrm{RHE}(\mathrm{pH}=14)$. Thus, on the respective RHE scales, the OER kinetic reference potential in alkaline is approx. $0.2 \mathrm{~V}$ lower than in acidic electrolyte. From the present analysis it appears possible that further improvement of OER electrocatalyst materials in alkaline conditions could enable OER onset potentials approaching the reversible equilibrium potential. Indeed, there exist experimental reports of certain electrocatalyst materials exhibiting OER activity at overpotentials $\lesssim 0.1 \mathrm{~V}$ w.r.t. RHE in alkaline electrolyte. $22 \sqrt{32}$

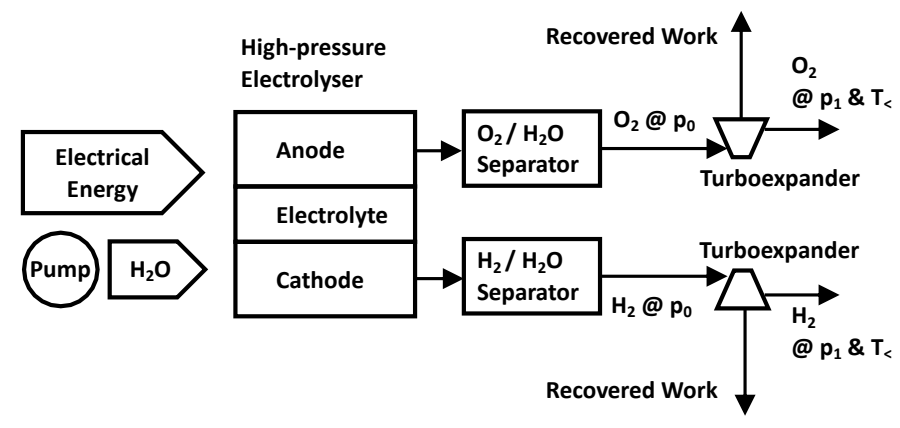

Fig. 4 Schematic process for energy recovery by high-pressure electrolysis combined with downstream turboexpanders that recover useful work from expanding high-pressure output gases.

\section{Pressure effect and energy recovery}

The present analysis also provides insight into the pressure effect in water electrolysis. At $T=25^{\circ} \mathrm{C}$, the kinetic reference voltage $U_{\text {kin }}=1.441 \mathrm{~V}$ is $0.212 \mathrm{~V}$ larger than the standard reversible cell voltage. This difference, i.e. the reactive excess overvoltage $\eta_{\text {rxs }}$, results from the very low concentrations of the $\mathrm{H}_{2}$ and $\mathrm{O}_{2}$ product gases, $c_{\mathrm{H}_{2} \text {,sat }}^{\ominus}$ and $c_{\mathrm{O}_{2} \text {,sat }}^{\ominus}$, respectively. Whereas these concentrations affect the rate of the water formation reaction $\mathrm{H}_{2}+1 / 2 \mathrm{O}_{2} \rightarrow \mathrm{H}_{2} \mathrm{O}$, they do not directly affect the reverse direction, i.e. the water splitting rate. At the kinetic reference voltage (7), the $\mathrm{H}_{2}$ and $\mathrm{O}_{2}$ gases are evolved at intrinsic pressure levels around the reactive pressures $p_{\mathrm{H}_{2}}^{\mathrm{R}}$ and $p_{\mathrm{O}_{2}}^{\mathrm{R}}$, respectively, which are $>1000$ bar, vide supra. Subsequently, the produced gas molecules escape from the electrolyte to the gas phase, e.g. by forming bubbles, thereby expanding to the externally defined pressure level of the respective electrolyser compartment. Therefore, as long as the water formation reaction (reverse direction) is negligible, which is generally the case for feasible operation conditions, the electrolyser pressure can be increased up to pressure levels of 1000 bar without increasing the cell voltage, i.e. electrical power input, at a given current density. This explains why experimental polarisation curves in high-pressure electrolysis did not shift to larger cell voltages. $\frac{51 \mid 54}{54}$

Energy recovery by high-pressure operation. This effect enables energy recovery via high-pressure electrolysis. Firstly, highpressure electrolysis can provide pressurised hydrogen "for free" for compressed storage. $\frac{54}{}$ Alternatively (or additionally), the high-pressure hydrogen and oxygen output gases could be expanded in expansion turbines (turboexpanders), thereby performing useful work, e.g. to drive a generator or some balance of plant equipment, as shown in Fig. 4 Adiabatic gas expansion inside turboexpanders from the electrolyser operation pressure $p_{0}$ to the final pressure $p_{1}<p_{0}$ would yield a recovered work

$$
W=n R T_{0} \frac{1}{\gamma-1}\left[1-\left(\frac{p_{0}}{p_{1}}\right)^{\frac{1}{\gamma}-1}\right]
$$

where $n$ is the molar amount of gas molecules, $T_{0}$ is the input gas temperature, and $\gamma$ is the heat capacity ratio of the expanding gas, i.e. $\gamma \approx 1.4$ for both $\mathrm{H}_{2}$ and $\mathrm{O}_{2}$. For an electrolyser operation temperature $T_{0}=80^{\circ} \mathrm{C}$ and pressure $p_{0}=100 \mathrm{bar}$ with subsequent 
expansion to $p_{1}=1$ bar, we obtain $W / n=5.37 \mathrm{~kJ} \mathrm{~mol}^{-1}$, which, in the limit $p_{0} / p_{1} \rightarrow \infty$, increases to $7.34 \mathrm{~kJ} \mathrm{~mol}^{-1}$. Considering one $\mathrm{H}_{2}$ and $1 / 2 \mathrm{O}_{2}$ molecules evolved per $\mathrm{H}_{2} \mathrm{O}$ involving the flow of $2 \mathrm{e}^{-}$, these energy recovery values are equivalent to a reduction of the cell voltage by $0.042 \mathrm{~V}$ and $0.057 \mathrm{~V}$, respectively. For an electrolyser operation voltage of $U_{\text {cell }} \approx 1.8 \mathrm{~V}$, this corresponds to an energy efficiency gain of the order of $2-3 \%$. Furthermore, the output gases of the adiabatic expansion process are extremely cold, which could be useful for cooling or liquefaction purposes.

If, instead, the output gases were expanded in an ideal isothermal process, the recovered work would equal $W=$ $n R T \log \left(p_{0} / p_{1}\right)$. Although isothermal expansion is practically difficult to achieve, it is interesting to note that if $p_{0}$ is set equal to the reactive pressures $p_{\mathrm{H}_{2} / \mathrm{O}_{2}}^{\mathrm{R}}$ and $p_{1}=p^{\ominus}=1 \mathrm{bar}$, the recovered energy from isothermal expansion would be exactly equivalent to the voltage difference between the kinetic reference voltage $U_{\text {kin }}$ and the standard reversible cell voltage $U_{\mathrm{rev}}^{\ominus}$. From a theoretical perspective, high-pressure electrolyser operation at pressure levels around $p_{\mathrm{H}_{2} / \mathrm{O}_{2}}^{\mathrm{R}}$ and voltages close to $U_{\text {kin }}$ in combination with energy recovery from isothermal gas expansion would thus bring the reversible efficiency $\varepsilon_{\text {rev }}$ close to $100 \%$ (based on atmospheric gas pressures). Although this is highly idealised, we conclude that high-pressure operation offers an intrinsic means for energy recovery in electrolysis of water.

\section{Conclusions}

The reversible equilibrium potential (or voltage) is not suited as an intrinsic kinetic reference for the electrochemical water splitting reaction in the liquid phase, because it is biased by the very low $\mathrm{H}_{2}$ and $\mathrm{O}_{2}$ product concentrations while, in fact, the latter do not directly influence the water splitting reaction direction. This imbalance is compensated in the definition of the kinetic reference potential (or voltage) by considering balanced reactive conditions for both reactants and products. The kinetic reference potential (or voltage) represents an intrinsic reference for kinetic analysis and it provides natural answers to several fundamental questions in the electrocatalysis of water splitting:

- Being numerically close to the thermoneutral voltage, the kinetic reference voltage explains why feasible water electrolysis rates set in only close to isenthalpic conditions, significantly above the reversible cell voltage.

- The pH-effects in HER and OER are quantified by $\mathrm{pH}$ dependent shifts of the respective kinetic reference potentials vs. the corresponding reversible potentials. The physical origin of these shifts is the protolytic water dissociation reaction which is rate limiting at the RHE potential for HER in alkaline conditions.

- The reason for the surprising pressure insensitivity of polarisation curves in high-pressure electrolysis is physically explained by the forward reaction, i.e. water splitting, being independent of the product concentrations. Only the rate of the reverse reaction, i.e. water formation, is increased at higher pressures of hydrogen and oxygen, but this rate is negligible at (and above) the kinetic reference voltage even for large operation pressures.

In this way, the analysis of the kinetic reference potential reveals an intriguing connection between kinetic overpotentials, $\mathrm{pH}$-effect, and pressure effect in the electrolysis of water. It further identifies alkaline OER as the most promising route for further electrocatalytic improvements. In acidic conditions, OER electrocatalyst materials such as $\mathrm{IrO}_{2}$ and $\mathrm{RuO}_{2}$ already provide OER activity close to optimum, and OER electrocatalysis research should focus on reducing noble-metal content. Furthermore, our analysis identifies high-pressure electrolysis as a means for energy recovery via subsequent expansion of pressurised output gases.

We believe that the concept of balanced reactive conditions and the kinetic reference potential will also reveal intriguing insight into the kinetics of other (electrochemical) reactions that involve large concentration changes, e.g. electrocatalytic carbon dioxide reduction or photocatalytic water splitting.

\section{Conflicts of interest}

There are no conflicts to declare.

\section{Acknowledgements}

T.B. acknowledges financial support in the form of a research fellowship grant funded by the SNSF (Swiss National Science Foundation). R.M. acknowledges financial support from the South African Department of Science and Innovation in the form of HySA/Catalysis Centre of Competence programme funding.

\section{Notes and references}

1 M. Ball and M. Weeda, International Journal of Hydrogen Energy, 2015, 40, 7903 - 7919.

2 M. R. Shaner, H. A. Atwater, N. S. Lewis and E. W. McFarland, Energy Environ. Sci., 2016, 9, 2354-2371.

3 S. B. Walker, U. Mukherjee, M. Fowler and A. Elkamel, International Journal of Hydrogen Energy, 2016, 41, 7717 - 7731.

4 M. Götz, J. Lefebvre, F. Mörs, A. M. Koch, F. Graf, S. Bajohr, R. Reimert and T. Kolb, Renewable Energy, 2016, 85, 1371 1390.

5 J. H. Montoya, L. C. Seitz, P. Chakthranont, A. Vojvodic, T. F. Jaramillo and J. K. Nørskov, Nature Materials, 2017, 16, 7081.

6 M. Kopp, D. Coleman, C. Stiller, K. Scheffer, J. Aichinger and B. Scheppat, International Journal of Hydrogen Energy, 2017, 42, 13311 - 13320 .

7 R. J. Detz, J. N. H. Reek and B. C. C. van der Zwaan, Energy Environ. Sci., 2018, 11, 1653-1669.

8 C. Hank, S. Gelpke, A. Schnabl, R. J. White, J. Full, N. Wiebe, T. Smolinka, A. Schaadt, H.-M. Henning and C. Hebling, Sustainable Energy Fuels, 2018, 2, 1244-1261.

9 S. Ardo, D. Fernandez Rivas, M. A. Modestino, V. Schulze Greiving, F. F. Abdi, E. Alarcon Llado, V. Artero, K. Ayers, C. Battaglia, J.-P. Becker, D. Bederak, A. Berger, F. Buda, E. Chinello, B. Dam, V. Di Palma, T. Edvinsson, K. Fujii, H. Gardeniers, H. Geerlings, S. M. H. Hashemi, S. Haussener, F. Houle, J. Huskens, B. D. James, K. Konrad, A. Kudo, P. P. Kunturu, D. Lohse, B. Mei, E. L. Miller, G. F. 
Moore, J. Muller, K. L. Orchard, T. E. Rosser, F. H. Saadi, J.-W. Schüttauf, B. Seger, S. W. Sheehan, W. A. Smith, J. Spurgeon, M. H. Tang, R. van de Krol, P. C. K. Vesborg and P. Westerik, Energy Environ. Sci., 2018, 11, 2768-2783.

10 C. Hank, L. Lazar, F. Mantei, M. Ouda, R. J. White, T. Smolinka, A. Schaadt, C. Hebling and H.-M. Henning, Sustainable Energy Fuels, 2019, 3, 3219-3233.

11 J. D. Cox, D. D. Wagman and V. A. Medvedev, CODATA Key Values for Thermodynamics, Hemisphere Publishing Corp., New York, 1989.

12 J. Rossmeisl, Z.-W. Qu, H. Zhu, G.-J. Kroes and J. K. Nørskov, Journal of Electroanalytical Chemistry, 2007, 607, 83-89.

13 J. Cheng, X. Liu, J. A. Kattirtzi, J. VandeVondele and M. Sprik, Angewandte Chemie International Edition, 2014, 53, 1204612050.

14 N. B. Halck, V. Petrykin, P. Krtil and J. Rossmeisl, Phys. Chem. Chem. Phys., 2014, 16, 13682-13688.

15 N. Danilovic, R. Subbaraman, K.-C. Chang, S. H. Chang, Y. J. Kang, J. Snyder, A. P. Paulikas, D. Strmcnik, Y.-T. Kim, D. Myers, V. R. Stamenkovic and N. M. Markovic, The Journal of Physical Chemistry Letters, 2014, 5, 2474-2478.

16 L. Trotochaud, S. L. Young, J. K. Ranney and S. W. Boettcher, Journal of the American Chemical Society, 2014, 136, 67446753.

17 R. V. Mom, J. Cheng, M. T. M. Koper and M. Sprik, The Journal of Physical Chemistry C, 2014, 118, 4095-4102.

18 M. S. Burke, S. Zou, L. J. Enman, J. E. Kellon, C. A. Gabor, E. Pledger and S. W. Boettcher, The Journal of Physical Chemistry Letters, 2015, 6, 3737-3742.

19 H.-S. Oh, H. N. Nong, T. Reier, A. Bergmann, M. Gliech, J. Ferreira de Araújo, E. Willinger, R. Schlögl, D. Teschner and P. Strasser, Journal of the American Chemical Society, 2016, 138, 12552-12563.

20 S. Geiger, O. Kasian, B. R. Shrestha, A. M. Mingers, K. J. J. Mayrhofer and S. Cherevko, Journal of The Electrochemical Society, 2016, 163, F3132-F3138.

21 V. Pfeifer, T. E. Jones, J. J. Velasco Vélez, C. Massué, M. T. Greiner, R. Arrigo, D. Teschner, F. Girgsdies, M. Scherzer, J. Allan, M. Hashagen, G. Weinberg, S. Piccinin, M. Hävecker, A. Knop-Gericke and R. Schlögl, Phys. Chem. Chem. Phys., 2016, 18, 2292-2296.

22 B. Dong, X. Zhao, G.-Q. Han, X. Li, X. Shang, Y.-R. Liu, W.H. Hu, Y.-M. Chai, H. Zhao and C.-G. Liu, J. Mater. Chem. A, 2016, 4, 13499-13508.

23 L. Giordano, B. Han, M. Risch, W. T. Hong, R. R. Rao, K. A. Stoerzinger and Y. Shao-Horn, Catalysis Today, 2016, 262, 2 -10 .

24 L. C. Seitz, C. F. Dickens, K. Nishio, Y. Hikita, J. Montoya, A. Doyle, C. Kirk, A. Vojvodic, H. Y. Hwang, J. K. Nørskov and T. F. Jaramillo, Science, 2016, 353, 1011-1014.

25 E. Fabbri, M. Nachtegaal, T. Binninger, X. Cheng, B.-J. Kim, J. Durst, F. Bozza, T. Graule, R. Schäublin, L. Wiles, M. Pertoso, N. Danilovic, K. E. Ayers and T. J. Schmidt, Nature Materials, 2017, 16, 925-931.
26 Y. Ping, R. J. Nielsen and W. A. Goddard, Journal of the American Chemical Society, 2017, 139, 149-155.

27 J. A. Gauthier, C. F. Dickens, L. D. Chen, A. D. Doyle and J. K. Nørskov, The Journal of Physical Chemistry C, 2017, 121, 11455-11463.

28 K. A. Stoerzinger, R. R. Rao, X. R. Wang, W. T. Hong, C. M. Rouleau and Y. Shao-Horn, Chem, 2017, 2, 668 - 675.

29 R. R. Rao, M. J. Kolb, N. B. Halck, A. F. Pedersen, A. Mehta, H. You, K. A. Stoerzinger, Z. Feng, H. A. Hansen, H. Zhou, L. Giordano, J. Rossmeisl, T. Vegge, I. Chorkendorff, I. E. L. Stephens and Y. Shao-Horn, Energy Environ. Sci., 2017, 10, 2626-2637.

30 T. Reier, H. N. Nong, D. Teschner, R. Schlögl and P. Strasser, Advanced Energy Materials, 2017, 7, 1601275.

31 C. Spöri, J. T. H. Kwan, A. Bonakdarpour, D. P. Wilkinson and P. Strasser, Angewandte Chemie International Edition, 2017, 56, 5994-6021.

32 M.-I. Jamesh and X. Sun, Journal of Power Sources, 2018, 400, $31-68$.

33 V. A. Saveleva, L. Wang, D. Teschner, T. Jones, A. S. Gago, K. A. Friedrich, S. Zafeiratos, R. Schlögl and E. R. Savinova, The Journal of Physical Chemistry Letters, 2018, 9, 3154-3160.

34 O. Kasian, S. Geiger, T. Li, J.-P. Grote, K. Schweinar, S. Zhang, C. Scheu, D. Raabe, S. Cherevko, B. Gault and K. J. J. Mayrhofer, Energy Environ. Sci., 2019, 12, 3548-3555.

35 G. Buvat, M. J. Eslamibidgoli, S. Garbarino, M. Eikerling and D. Guay, ACS Applied Energy Materials, 2020, 3, 5229-5237.

36 G. Buvat, M. J. Eslamibidgoli, A. H. Youssef, S. Garbarino, A. Ruediger, M. Eikerling and D. Guay, ACS Catalysis, 2020, 10, 806-817.

37 S. Divanis, T. Kutlusoy, I. M. Ingmer Boye, I. C. Man and J. Rossmeisl, Chem. Sci., 2020, 11, 2943-2950.

38 Y. Pu, M. J. Lawrence, V. Celorrio, Q. Wang, M. Gu, Z. Sun, L. A. Jácome, A. E. Russell, L. Huang and P. Rodriguez, J. Mater. Chem. A, 2020, 8, 13340-13350.

39 W. Sheng, H. A. Gasteiger and Y. Shao-Horn, Journal of The Electrochemical Society, 2010, 157, B1529.

40 D. Strmcnik, M. Uchimura, C. Wang, R. Subbaraman, N. Danilovic, D. van der Vliet, A. P. Paulikas, V. R. Stamenkovic and N. M. Markovic, Nature Chem., 2013, 5, 300306.

41 J. Durst, A. Siebel, C. Simon, F. Hasché, J. Herranz and H. A. Gasteiger, Energy Environ. Sci., 2014, 7, 2255-2260.

42 W. Sheng, Z. Zhuang, M. Gao, J. Zheng, J. G. Chen and Y. Yan, Nat. Commun., 2015, 6, 5848.

43 C. Zalitis, J. Sharman, E. Wright and A. Kucernak, Electrochimica Acta, 2015, 176, 763 - 776.

44 T. Shinagawa, A. Garcia-Esparza and K. Takanabe, Sci. Rep., 2015, 5, 13801.

45 Y. Zheng, Y. Jiao, Y. Zhu, L. H. Li, Y. Han, Y. Chen, M. Jaroniec and S.-Z. Qiao, Journal of the American Chemical Society, 2016, 138, 16174-16181.

46 J. Rossmeisl, K. Chan, E. Skúlason, M. E. Björketun and V. Tripkovic, Catalysis Today, 2016, 262, 36 - 40. 
47 Q. Wang, Z. L. Zhao, S. Dong, D. He, M. J. Lawrence, S. Han, C. Cai, S. Xiang, P. Rodriguez, B. Xiang, Z. Wang, Y. Liang and M. Gu, Nano Energy, 2018, 53, 458 - 467.

48 A. R. Zeradjanin, G. Polymeros, C. Toparli, M. Ledendecker, N. Hodnik, A. Erbe, M. Rohwerder and F. La Mantia, Phys. Chem. Chem. Phys., 2020, 22, 8768-8780.

49 C. Hu, L. Zhang and J. Gong, Energy Environ. Sci., 2019, 12, 2620-2645.

50 I. Ledezma-Yanez, W. D. Z. Wallace, P. Sebastián-Pascual, V. Climent, J. M. Feliu and M. T. M. Koper, Nature Energy, 2017, 2, 17031.

51 S. Grigoriev, M. Khaliullin, N. Kuleshov and V. Fateev, Russian Journal of Electrochemistry, 2001, 37, 819-822.

52 S. Grigoriev, V. Porembsky and V. Fateev, International Journal of Hydrogen Energy, 2006, 31, 171 - 175.

53 M. Suermann, T. J. Schmidt and F. N. Büchi, Electrochimica Acta, 2016, 211, 989 - 997.

54 M. Suermann, A. Pătru, T. J. Schmidt and F. N. Büchi, International Journal of Hydrogen Energy, 2017, 42, 12076 - 12086.

55 IUPAC Solubility Data Series Volume 5/6, Hydrogen and Deuterium, ed. C. L. Young, Pergamon Press, Oxford, 1981.

56 IUPAC Solubility Data Series Volume 7, Oxygen and Ozone, ed. R. Battino, Pergamon Press, Oxford, 1981.
57 NIST Chemistry WebBook, NIST Standard Reference Database Number 69, ed. P. J. Linstrom and W. G. Mallard, National Institute of Standards and Technology, Gaithersburg MD, 20899, 2018.

58 U. Babic, M. Suermann, F. N. Büchi, L. Gubler and T. J. Schmidt, Journal of The Electrochemical Society, 2017, 164, F387-F399.

59 P. Datt, in Latent Heat of Vaporization/Condensation, ed. V. P. Singh, P. Singh and U. K. Haritashya, Springer Netherlands, Dordrecht, 2011, pp. 703-703.

60 C. Niether, S. Faure, A. Bordet, J. Deseure, M. Chatenet, J. Carrey, B. Chaudret and A. Rouet, Nat. Energy, 2018, 3, 476-483.

61 M. Eigen and L. De Maeyer, Zeitschrift für Elektrochemie, Berichte der Bunsengesellschaft für physikalische Chemie, 1955, 59, 986-993.

62 D. F. Abbott, D. Lebedev, K. Waltar, M. Povia, M. Nachtegaal, E. Fabbri, C. Copéret and T. J. Schmidt, Chemistry of Materials, 2016, 28, 6591-6604.

63 A. Hartig-Weiss, M. Miller, H. Beyer, A. Schmitt, A. Siebel, A. T. S. Freiberg, H. A. Gasteiger and H. A. El-Sayed, ACS Applied Nano Materials, 2020, 3, 2185-2196.

64 C. F. Dickens, C. Kirk and J. K. Nørskov, The Journal of Physical Chemistry C, 2019, 123, 18960-18977. 